\title{
Legitimacy, Adaptation, and Resilience in Ecosystem Management
}

\author{
$\underline{\text { Barbara A. Cosens }}{ }^{1}$
}

\begin{abstract}
Ecologists have made great strides in developing criteria for describing the resilience of an ecological system. In addition, expansion of that effort to social-ecological systems has begun the process of identifying changes to the social system necessary to foster resilience in an ecological system such as the use of adaptive management and integrated ecosystem management. However, these changes to governance needed to foster ecosystem resilience will not be adopted by democratic societies without careful attention to their effect on the social system itself. Delegation of increased flexibility for adaptive management to resource management agencies must include careful attention to assuring that increased flexibility is exercised in a manner that is legitimate and responsive to the social system. Similarly, democratic systems proceed in incremental steps and are not likely to adopt wholesale changes to achieve integrated ecosystem management. This paper uses the concept of legitimacy in governance as a necessary component of any change to achieve greater social-ecological resilience and will turn to network theory as a means to facilitate legitimacy across multiple jurisdictions.
\end{abstract}

Key Words: adaptive governance; ecosystem management; law; legitimacy; networks; policy; resilience

\section{INTRODUCTION}

Managing for sustainability of ecological systems requires development of processes for governance that account for the complexity and uncertainty of the social-ecological system. The emerging ecological concept of resilience provides an umbrella theory for integrating concepts of ecosystem management with ecological response to achieve sustainability (Walker et al. 2004).

Resilience is a measure of the amount of perturbation a socialecological system can withstand and still maintain the same structure and functions; it addresses the ability of a complex system to continue to provide a full range of ecosystem services in the face of change. (Holling 1973, Holling and Gunderson 2002, Walker et al. 2004, Walker and Salt 2006). By viewing governance in a way that recognizes the social and ecological systems as linked, resilience can be enhanced both from the natural adaptive capabilities of the ecological system and from the ability of the social system to respond to an ecological problem by seeking to restore the ecosystem (Folke et al. 2005, Zellmer and Gunderson 2009) or to prevent harm. However, resilience in the context of the social part of a social-ecological system must be viewed as more than a means to alter how the social system interacts with the ecological system to ensure ecological resilience. The key difference between social and ecological systems is that the actors in the social system have the ability to exercise free will and conscious thought. Thus, the social system may choose whether or not to foster resilience in the ecological system (Walker et al. 2004, Folke et al. 2005). It is the goal of this research to focus on procedural elements of governance needed to increase the likelihood that the choice to foster resilience is made.
Given the high degree of uncertainty and complexity in ecological systems, adaptive management, a process that involves incremental changes and adjustments to management as the consequences of various feedbacks become clear through monitoring, has emerged as a recommended approach to manage for ecological resilience (Holling 1978, Lee 1999, Folke et al. 2005, Walker et al. 2004, Huitema et al. 2009). Barriers to achieving adaptive management include the fact that science alone is insufficient to convince social systems to accept a particular decision. In addition, just as resilience theory recognizes the multiple scales and cross-scale interactions affecting ecosystems, governance occurs at multiple scales and governance scales do not always mimic those of ecosystems. This paper focuses on two components of process that will be needed to help bridge the gap between the type of adaptive response suggested by ecologists and the decision making process in a system of governance: (1) procedural elements to assure legitimacy in governance; and (2) coordination across scales of governance to assure that legitimacy carries through various scales of decision making. These procedural components are presented as necessary to achieving resilience while recognizing they are not sufficient in themselves.

\section{RESILIENCE THEORY AND ECOSYSTEM MANAGEMENT}

The traditional approach to ecosystem management involves a one-way flow of management by the social system with services from the ecological system in return. The focus is generally on the optimization of limited aspects of an ecological system and suffers from the failure of synthesis to accurately represent the emergent behavior of the system (Cosens 2010). The failure of management through 
"optimization" to retain the full range of ecosystem services is a key message of scholars working on the concept of resilience (Zellmer and Gunderson 2009).

Optimization, although intended to prevent loss of the targeted component of the ecological system, not only fails to address the complexity of the ecological system, it fails to account for the complex feedback between the social and the ecological system (Walker and Salt 2006). It ignores the basic feature of complexity, that there will be a high level of uncertainty surrounding the potential consequences of a particular action. Resilience theory provides a framework for moving from management through optimization to a more adaptive form of management based on recognition of the complexity of an ecological system and designed both to prevent adverse scenarios from occurring and to adapt when change inevitably does occur. It provides a framework for development of governance to enhance the sustainability of the socialecological system. Because this paper attempts not only to bridge the social-ecological divide, but the divide between resilience theory and law, it is necessary to begin by defining certain concepts because they will be used for these purposes.

Although variations exist, there is a general consensus among resilience theorists concerning the concepts critical to discussing and applying resilience theory to ecological system management. In discussing resilience theory a distinction must be drawn between engineering and ecological resilience. Although both resilience theories share many traits, "they differ in terms of the mechanisms and strategies the systems use to avoid being pushed so far as to be functionally restructured. The engineering resilience strategy is to devote all system resources to staying near to the equilibrium, the goal being to snap back, whereas the ecological resilience strategy accommodates the possibility of moving relatively far from the equilibrium, with the goal being to avoid "flips" from one structural state to another" (Ruhl 2011:1377). This paper is focused on ecological resilience.

To apply resilience theory to governance it is also necessary to define the use of terms related to ecosystem management. In resilience literature, scholars use the term governance to describe the laws, policies, regulation, institutions, and institutional structure involved in governing (Folke et al. 2005, Huitema et al. 2009). Much of the literature calls on adaptive management/governance to achieve resilience (Lee 1999, Folke et al. 2005, Huitema et al. 2009). The term "adaptive management" has been used to describe a process of learning through monitoring ecosystem response to a particular action, followed by incremental change in the action based on what is learned (Lee 1999, Folke et al. 2005, Huitema et al. 2009) and generally applies to management action by a single entity.

Boyle et al. (2001:122) help clarify the difference between governance and adaptive management by stating that "governance is the process of resolving trade-offs and of providing a vision and direction for sustainability, management is the operationalization of this vision ..." Huitema et al. (2009) set forth four criteria for adaptive governance: polycentricity, also referred to as legal pluralism in legal scholarship (Roth et al. 2005), public participation, an experimental approach to resource management, and management at the bioregional scale. Thus, "adaptive governance" includes the process of adaptive management, but also reflects the collaboration and cooperation across different levels of government and agencies, often with overlapping authority, nongovernmental and individual action apparent in a complex system (Folke et al. 2005). Governance includes the processes of choosing among conflicting interests over resource use and nonuse, and of setting goals for a particular social-ecological system (Boyle et al. 2001). Thus, adaptive governance is the term used when referring to action by multiple jurisdictions and to the process of involving multiple nongovernmental actors in decision making (Cosens and Williams 2012). The concept of adaptive governance captures the approach needed to foster resilience in the ecological system, but does not capture all the elements needed for social acceptance in democratic nations. In seeking to bridge concepts of resilience to approaches to governance, changes in management must include measures to assure the social acceptance of management decisions. Within this context, the aspect of adaptive governance addressed by this paper is the procedures necessary to increase the likelihood that an adaptive approach that fosters resilience will be chosen and can function across multiple scales of governance and ecological systems.

\section{BRIDGING RESILIENCE THEORY AND ADAPTIVE GOVERNANCE TO LAW}

Similar to the consideration of resilience terminology, it is necessary to explain the legal terminology used in this article. Substantive laws govern what is managed, who is regulated, and the goal of that management or regulation. Administrative law governs how these functions are implemented (Stewart 2003), and is the focus of this paper. The term administrative law is used in this article to refer to any law governing the process of agency or governing body decision making; for example, even though found in substantive law, this article uses the term "administrative" law for process requirements such as those found in the Environmental Impact Statement requirements of the U.S. National Environmental Policy Act (42 U.S.C. $\S \S 4321$ et seq.) or the requirement of consultation in the Endangered Species Act (ESA; 16 U.S.C. § $\S 1531-1544)$. The procedural changes in the law to facilitate the acceptance of adaptive governance can be addressed through the concept of legitimacy.

\section{LEGITIMACY}

It is a basic tenant of political theory that people seek legitimacy in the actions of those who govern them (Bodansky 
1999). Democracy therefore emerges as a system with a high level of legitimacy, because through the process of electing those who govern, people consent to their leadership. However, when democratic nations move from implementation of the law by elected officials to delegation of authority to administrative agencies or appointed governing bodies, they dilute the direct connection between the elected official and the voters affected by regulation. As the administrative state has grown, administrative law governing the process by which agencies or appointed bodies take action has developed to fill this gap in direct accountability. The direct accountability gap increases with the scale of governance (Esty 2006). Thus, local agencies may have a higher perception of legitimacy than federal or international entities. At the local scale, fewer formal protections are needed to assure accountability to the regulated public. The introduction of flexibility to ecosystem management challenges traditional sources of legitimacy, thus presenting a barrier to adoption of new approaches. It is through the use and modification of administrative law that these challenges can be met.

Daniel Esty (2006) outlines five sources of legitimacy applicable to administrative entities in addition to the democratic process. These five sources form a framework to discuss additional changes to administrative law necessary to assure legitimacy in a more adaptive approach to ecosystem management. The five sources are: (1) results-based: legitimacy derived from the fact that decisions are based on objective expertise and the results can be determined to be good; (2) order-based: legitimacy based on the fact that rules are clear, stable, and publicly available; (3) systemic: legitimacy based on the existence of checks and balances among institutions; (4) deliberative: legitimacy based on the inclusion of a public dialog in the process of decision making; and (5) procedural: legitimacy derived from an open and transparent process of decision making and an explanation for the choices made.

Richard Stewart's review of the history of development of U. S. administrative law in the 21st century (Stewart 2003) helps illustrate its importance in addressing concerns with legitimacy as larger and more powerful agencies were established to address emerging societal problems, including those involving the environment. To illustrate the importance of process in rendering decisions legitimate, it is useful to correlate those developments to the five sources of legitimacy outlined above, then to place adaptive management in the context of each particular source of legitimacy. In addition to being insufficient to assure legitimacy in management decision making when greater flexibility is delegated, these mechanisms are not necessarily available when multijurisdictional management, is involved. Assuring legitimacy across multiple jurisdictions is discussed below. The following discussion is placed in the context of U.S. federal administrative law; the concepts are applicable at any governmental system struggling to implement ecosystem management across multiple jurisdictions.

\section{Results-based legitimacy}

Results-based legitimacy reliant on agency scientific expertise began in the United States with Gifford Pinchot's call for scientific, federal management of the forests and establishment of the National Forest Organic Act in 1897. (16 U.S.C. $\S \S 473-478,479-482$ and 551, June 4, 1897, as amended 1905, 1911, 1925, 1962, 1964, 1968, and 1976) The infusion of science into decision making has at its very core the belief that the process will be more objective and the results better. Reliance on scientific expertise is increasingly questioned as a source of legitimacy because agency science shows vulnerability to politicization (Wagner 1995, Doremus 2005, Ruhl and Salzman 2006, O'Reilly 2007, Cosens 2008). Statutory language requiring use of "best available science," (e.g., U.S. Safe Drinking Water Act 42 USC §300g-1) has been adopted in some environmental laws because trust for objective science-based decision making has eroded. However, exactly what is the "best available science" when decision making involves areas of scientific uncertainty is often unclear and that uncertainty can be used to distort decision making in favor of a particular political agenda (Wagner 1995, Doremus 2005, Ruhl and Salzman 2006, O'Reilly 2007, Cosens 2008).

In contrast to the discussion of the other four sources of legitimacy where additional changes are needed to ensure legitimacy, adaptive management can actually enhance results-based legitimacy (Camacho 2009). The problem for results-based legitimacy lies more in the improper implementation of adaptive management than in the move to a more flexible means of management. Adaptive management, by definition, requires that the results of an agency action be monitored and that the action be adjusted based on the monitoring. However, despite lip service to increasing use of adaptive management by agencies, data are rarely gathered to verify the outcome of a particular action once it is taken (Camacho 2009). Furthermore, even if data were collected following agency action, agencies rarely have the authority to modify the action.

Reluctance to implement adaptive management lies, in part, in failure to tie adjustment based on monitoring to agency accountability. By imposing a requirement that progress toward a particular goal must be accounted for and adjustment made in the face of new data, the use of science to achieve the goals of an interest group rather than the goal of a statute can be reduced. In this way, legitimacy is served by adaptive management.

\section{Order-based legitimacy}

Order-based legitimacy captures the concepts of stability and finality, or at least predictive capability, regarding application of the law. The expectation that rules will be stable and that 
finality can be achieved may present the most significant barriers to authorization of the flexibility needed to implement adaptive management. The expectation for finality is at the core of many legal battles concerning the environment and can be characterized as a basic conflict between science and law. In simple terms, science is a search for the truth, whereas litigation is a search for finality (Cosens 2008). Scientific inquiry has no statute of limitations, no concept of res judicata. Scientific methodology is a process of disproving what was formerly thought to be true, of reinvestigating questions thought solved, of reinterpreting information in light of new discoveries (Kosso 2007). In contrast, civil litigation is designed to finalize a dispute, to provide a forum where, no matter how flawed the inquiry, a peaceful final resolution of a dispute can be achieved.

In environmental disputes, finality serves those with economic interests in the environment by providing stability for investment, whereas science serves those concerned with sustaining the environment itself by continuing the search for the true impacts of human action on the ecological system. The fact that one side (the environmental side) of the litigation equation seeks equal treatment for goals not served by civil litigation destabilizes the system. Once a court provides a final answer, the issues will be revisited with another legal theory. Once the judicial system is exhausted, the issues will be revisited in the legislature. Once the political system is exhausted, the issues will be addressed through civil disobedience. It is this reality, the fact that finality is often not achieved through the current system of resolving environmental disputes, that encourages a more incremental and collaborative approach.

Legitimacy in implementation of adaptive management will require an approach that gives equitable treatment to both the economic need for finality and the progress toward the true system understanding needed to address environmental concerns. Anecdotal evidence suggests that currently, management relying on monitoring for adjustment uses a biologic timeframe when the management action is developed by a science-based agency (see e.g., USGS 2011, basing monitoring on biological goals), and social timeframes when negotiated (see e.g., Nez Perce Tribe, State of Idaho, and United States Federal Government 2004, placing a 30 year timeframe on a biological opinion to prevent jeopardy for listed salmon and steelhead populations, to provide stability for water users in the region). However, to foster ecological resilience while maintaining legitimacy both ecological and social timeframes must be considered when setting the pace of incremental change. To place this in more practical terms, it is a waste of resources to require reconsideration of a particular action when it is too soon for the biologic system to register change. At the same time, tying the adjustment cycle to a 30 year development loan cycle may prevent adjustment in time to prevent irreversible harm. At the other end of the spectrum, short-term human interests that tend to coincide with the elections cycle must not control the pace, yet must be factored in seeking new approaches to management. A process of negotiated timeframe setting in which both the biologic and social timeframes are brought to the table with the goal of providing stability while preventing irreversible harm is recommended. It would be naïve to suggest that this goal makes the negotiation any easier, but when combined with the transparency and deliberative requirements, it may avoid an approach that favors only one aspect of the social-ecological system.

\section{Systemic legitimacy}

Systemic legitimacy is provided by the various checks over agencies provided by both the judicial and legislative branch. The ability to challenge an agency decision in court provides greater assurance that decisions will be made within the boundaries of the authorizing legislation and constitutional limits. Separation of the legislative branch of government from the implementing branch provides a check on unilateral exercise of power. Movement toward adaptive management should not eliminate various checks and balances and they will not be treated in detail here. Instead, an additional systemic check may be provided in the network approach to coordination. A more open and frequent exchange of information, harmonizing of rules, and periodic collaboration across agencies and jurisdictions may prevent undue influence at a particular level and can open decision making to broader expert scrutiny. Multiscale checks may prove effective in diluting agency capture and in bringing the public voice to decision making as required by deliberative legitimacy.

\section{Deliberative legitimacy}

Deliberative legitimacy is reflected in the growing expectation and provision for public comment in numerous aspects of agency decision making from the requirement of notice and comment in rulemaking to the increasing use of public meetings to gain support for a decision. In the United States, the passage of the National Environmental Policy Act (NEPA) in 1969 can be considered the major turning point in public involvement in agency decision making (Hirt and Sowards 2012). Unlike the requirements that meetings and records be open to the public, NEPA imposes the affirmative duty on agencies to develop, analyze, and provide to the public for comment, information on the environmental impact of major federal actions (U.S. National Environmental Policy Act 42 USC §4332). Although NEPA does not impose any substantive requirement to choose the most environmentally sustainable alternative (Vermont Nuclear Power Corp. v. NRDC, 435 U.S. 519 [1978]), it arms the public with the information necessary to participate in shaping the decision through the political process.

Implementation of adaptive management provides an excellent opportunity to employ some of the newer methods 
of public involvement (Bingham 2009). It lends itself to use of a procedure similar to negotiated rulemaking, in which the agency collaborates with the regulated community and interested parties to develop a rule for reaching decisions on incremental changes in management. Small scale (spatial and temporal) impacts may be reflected best in local knowledge, thus a more collaborative process may improve the knowledge base for the decision. A more collaborative approach to management could also make use of the interagency networks in the context of response scale to allow coordination of adaptation and avoid unintended consequences of agency action. The network approach may be necessary to allow for manageable public input on jurisdictionally complex ecosystems.

\section{Procedural legitimacy}

Procedural legitimacy is provided by transparency and is reflected in many of the administrative requirements for notice and comment, and the availability of judicial review. In addition, beginning with the passage of the Freedom of Information Act in 1966, (Public Law 104-231 codified at 5 USC §552) U.S. agencies must provide documents to citizens on request. Not only must records be open to the public, but meetings at which a decision might be made must be noticed and open to the public (5 USC 552b). Finally, the availability of judicial review of agency action extends to review of compliance with agency procedural rules (5 USC §706(2)(D)). Existing administrative procedures requiring open records, meetings, notice, and comment must apply to incremental decision making in adaptive management to assure procedural legitimacy, but must also extend to the level of international bodies when transboundary resources are involved.

Incorporation of measures to assure legitimacy in proposed changes to ecosystem management to allow a more adaptive approach will enhance both management outcomes and public acceptance, thus fostering both social and ecological resilience. However, applying these concepts of legitimacy to a complex social-ecological system requires moving from discussion of management by a single entity to management by multiple entities, jurisdictions, and at multiple levels. It necessitates a means to coordinate and collaborate across multiple jurisdictions and to manage meaningful deliberative processes. As noted by Lee (1993:28) in reference to the Columbia River Basin, "[e]ach of the major uses of the basin's resources is managed by a different constellation of human institutions, each set of managers guards its rights and prerogatives, and none is sufficiently powerful to bring the others to heel. Multiple management of multiple uses produces a tragedy of the commons." Nevertheless, multiscalar, diverse, overlapping authority can facilitate resilience in governance systems, provided an adequate mechanism for coordination across the particular ecological system is developed.

\section{COORDINATION AND COLLABORATION ACROSS MULTIPLE JURISDICTIONS}

The procedural measures discussed above foster legitimacy at a single scale of governance or within an agency with a defined scope of authority, but governance across an entire ecosystem is rarely so simple. Furthermore, we do not write with a clean slate. Jurisdictional boundaries and scales of governance may ignore ecosystem boundaries for historic, cultural, or other reasons unrelated to the needs of ecosystem management. Resistance to change and slow incremental process with which it occurs in a democratic system imposes a pragmatic requirement that recommendations for changes in governance begin with the current jurisdictional context as a baseline. Rather than suggest a new form of governance, this article is the beginning of a research effort seeking to make use of the existing diversity and multiple scales of ecosystem governance while developing means to integrate across and within various scales.

Cross-scale interactions may undermine legitimacy. A local land use decision to build in a river floodplain may lead to increased need for investment in storage across an international boundary. Complicating the scale issue even more are situations in which the source of the problem and the negative impact occur at different scales thus removing any incentive for action at the scale of the problem source (Long 2009). This situation highlights the need for response capacity at multiple, linked scales. In the United States this mismatch has resulted in a backlash to some environmental laws passed in the 1970s. For example, the failure of states to take action led to federal regulation to achieve clean water (Federal Water Pollution Control Act [Clean Water Act], 33 U.S.C. § $\S$ 1251-1387), clean air (Clean Air Act [CAA], 42 U.S.C. $\S$ $\S 7401-7671 q$ ), and species protection (Endangered Species Act [ESA] 16 U.S.C. $\S \S 1531-1544)$. However, although the scale of the problem is federal, the source may be local land use planning in the case of nonpoint source pollution (Adler et al. 1993), or local development of wetlands important to filtration of polluted water and flood mitigation on a larger scale (Rapanos v. United States, 547 U.S. 715 [2006]; Cosens 2008), or local development that will endanger an obscure species important to biodiversity in general (National Association of Home Builders v. Babbitt, 130 F.3d 1041, 1059 [D.C. Cir. 1997], cert. denied 524 U.S. 927 [1998]). Local burden/large scale benefit has contributed to the backlash against environmental regulation in the U.S. in recent years. Legitimacy in decision making is lost if conscious recognition of these cross-scale linkages is not accounted for in the process. If the ecological system will not allow us to ignore the linkage among scales, then it is advisable to approach the linkages among agencies and jurisdictions consciously and build them to facilitate adaptation.

Adaptive governance moves from a focus on efficiency and clean lines between jurisdictional authorities, to a focus on 
diversity, redundancy, and multiple levels of management, including a role for local knowledge and local action. The adaptive state of systems at scales above and below the scale of a system of interest may enhance or detract from the resilience of the system of interest (Walker et al. 2004, Walker and Salt 2006). An outgrowth of the study of resilience in ecological systems is the development of the concept of the adaptive cycle to describe the state and evolution of a selforganizing system and panarchy theory to describe the hierarchical structure of adaptive cycles linked across scales (Holling 2001, Holling and Gunderson 2002). These concepts provide a useful metaphor when considering governance across multiple jurisdictions.

The adaptive cycle described by Holling (2001) contemplates the possibility of a collapse phase that leads to innovations, some of which will succeed. The idea that management for resilience could mean allowing collapse of a system does not instill faith in the approach by those who recognize stability as one of the key factors in economic success. But panarchy recognizes that adaptive cycles occur at many scales and that linkage occurs across scales. The premise of the concept of panarchy is that there will be linkage among the results of actions at different scales whether or not strict legal lines are drawn between authorities and jurisdictions. Higher, slower cycles may provide stability for smaller scales to engage in innovation and adaptation while minimizing the risk of collapse (Holling 2001, Holling and Gunderson 2002). Innovation and adaptation at smaller scales can feedback to the maintenance of stability at larger scales. Viewed from the perspective of the U.S. system, stable federal and state law can provide room for local innovation. Similarly, stable EU policy may provide room for member state innovation while providing a forum for coordination and information exchange. Nested scales of management authority thus allows for adaptation while providing large scale stability. Although matching the scale of governance to the scale of the problem may be a theoretical goal (Ruhl and Salzman 2010), the scale appropriate for one problem may not be relevant for another (Ruhl and Salzman 2010), nor do complex systems always have clearly identifiable scales for governance (Ruhl and Salzman 2010). Thus, development of networks across scales will account for the fact that although coordination may be needed across an entire ecosystem, issues will arise at a variety of scales.

Two changes are needed to facilitate adaptable response at multiple scales: (1) increased local capacity; and (2) vertical and horizontal networks across jurisdictions and scales to allow coordinated response among overlapping authorities without high transaction costs.

The need for local capacity with robust networks to multiple levels can be seen more clearly if the example used is a sudden, high-risk situation. It is on the local level, not the level of an entity like the U.S. Department of Homeland Security, that a major portion of the resources are needed for response to a high risk emergency like Hurricane Katrina in New Orleans. However, without the link to assistance both from other communities and from state, national, and international levels, a disaster of such magnitude will be beyond the capacity of any local government. Studies of postdisaster short and longterm relief indicate that networks for coordination and clear definition of roles must be addressed prior to a disaster if local organizations are to be effectively used in providing relief (Stys 2011).

Taking the example of emergency response further, a proven and highly robust system for multiagency/jurisdiction networking is the incident command system for multijurisdictional response to a large-scale, often mass casualty, emergency. The incident command system facilitates multientity response to an emergency in which the scale and timing was highly uncertain prior to its occurrence (see e.g., U.S. Forest Service 2000, U.S. Department of Homeland Security 2012). Rather than create a new agency at the scale of every conceivable emergency, the networks provide a means for rapid crisis response across multiple agencies at the same scale and through multiple scales of agencies. Under this system no more than seven people or entities report to the incident commander, no more than seven to each of those seven, etc., until the on-the-ground response to, for example, a wildfire, a flood, or an earthquake, may involve hundreds or even thousands of people. In the author's experience as a search and rescue volunteer, the initial hours or even days of response to a large scale emergency are often chaotic, however, within a remarkably short period of time a relatively smooth operation emerges in which information and coordination of decisions in response to changes in the problem flow rapidly within and between levels. Although referred to by some as a "command and control" approach (Stys 2011), the incident command system is highly adaptive to meet the type, location, and scale of a disaster. The result is a clear line of hierarchical authority leading to the "command and control" description possibly necessary in a high risk situation. However, it is the ease of formation of networks for flow of information and resources made possible by the conscious focus on cross-entity and cross-scale coordination that serves as a lesson for ecosystem management.

Much of the change and uncertainty in an ecosystem does not occur on the time scale of an emergency. Establishment of networks for management of slower processes in aquatic ecosystems also exist in, for example, the move toward integrated water resource management (Global Water Partnership 2000 and 2002, European Union 2000). A formal structure for integrated water resource management does not currently exist in the United States, and yet studies show that "weak ties" are nevertheless formed among individuals working at various levels of government and nongovernmental 
organizations when large scale ecological issues arise (Ruhl and Salzman 2010).

Effective networks rely on the existence of certain social skills among people within a network rather than a formal, mandatory network structure (Folke et al. 2005). This is consistent with the author's experience in multijurisdictional water negotiations in which success is often determined by key personalities involved (Cosens 1998). Administrative law and institutional structure cannot mandate the individuals involved, but could be designed to maximize diversity, thus increasing the likelihood that these personality types are represented. Clearly there is also a role for institutions of higher education to provide students with the skills necessary to bring people together and to communicate across boundaries.

Any solution formalized in administrative process must strike a balance between facilitation of network formation and avoidance of a rigid structure that cannot adapt to changing scale and differing types of problems. Lessons can be taken from experience with systems like the incident command system for emergency response to improve the capacity of networks to form and act adaptively and to design administrative law to facilitate flexibility.

First, coordination and communication among different entities works better if it is express (Bingham 2009). Thus, it must be a requirement and assigned position within each entity. Establishment of a network framework upfront can also avoid transaction costs encountered with the ad hoc development of a network after a problem is identified (Huitema et al. 2009). Second, frequent information sharing among entities may serve as a building block in the relationships necessary for multijurisdictional decision making. Third, substantial resources must be devoted to the local scale. The current structure of resource availability, both with respect to funding and people, for entities that manage ecosystems may need to be inverted, with greater resources made available at the local rather than national scale. Fourth, harmonization of methods and regulations in the area of overlap will result in more effective networks (Zaring 2009). Fifth, attention must be given to striking the proper balance between cohesion and diversity of network membership to foster creative solutions, use of local knowledge, and adaptive capacity. Through study of the topology of networks, scholars have begun to identify key characteristics of effectiveness (Bodin and Crona 2009). Although intuitively it might seem that a cohesive group would be more likely to achieve selfregulation, complex problems require a more diverse membership.

Finally, attention must be paid to the difference between formal and informal networks. To effectively manage across multiple entities, networks with low transaction costs are needed (Huitema et al. 2009). One way to achieve this is to build network formation into administrative process rather than leaving it to be formed on an ad hoc basis when a problem arises. Models for coordination across entities and scales imbedded in administrative law could greatly reduce these transaction costs. At the same time, caution is warranted in any attempt to formalize the interaction across entities and scales before understanding existing informal networks for communication and action. Research by Bodin and Crona (2009) suggest that informal networks appear to be more successful than an imposed structure. Informal network formation can be facilitated through capacity building, identification of influential actors through use of social network analysis prior to establishing lines of coordination, encouraging broad participation, and providing a forum for communication (Bodin and Crona 2009).

\section{CONCLUSION}

Moving from ecosystem management concepts designed to handle uncertainty, to implementation by governance systems requires careful attention to procedural elements to assure legitimacy in implementation. Two areas of administrative process may aid in reducing barriers to implementation of a more adaptive approach to management and scale issues associated with multiple jurisdictions: (1) procedural elements to assure legitimacy in governance; and (2) coordination across scales of governance to assure that legitimacy carries through various scales of decision making.

If resilience based management is chosen, restructuring the current system is no small task. This paper looks primarily at the administrative framework that must change from the model of massive state and federal agencies to an infusion of resources and capacity building at the local level, while retaining overlapping state, federal, and international programs to provide oversight and research and to coordinate across multiple jurisdictions. Such reform will require authorization for greater flexibility in decision making while relying on public participation and input as a large source of accountability. It will require expenditures on monitoring the effects of decisions and the flexibility to respond to the results of monitoring. In short, the recognition of the complexity in the social-ecological system, coupled with a growing realization of the complete dependence of the human race on the ability of the ecological system to serve it, requires reform of the administrative state to allow society to responsibly respond to the challenge of managing human interaction with ecosystems.

Responses to this article can be read online at: http://www.ecologyandsociety.org/issues/responses. php/5093 


\section{Acknowledgments:}

I would like to thank Jonas Ebbesson for bringing me to the Stockholm conference on Law and Resilience to begin this discussion.

\section{LITERATURE CITED}

Adler, R. W., J. C. Landman, and D. M. Cameron. 1993. The Clean Water Act 20 years later. Island Press, Washington, D. C., USA.

Bingham, L. B. 2009. Collaborative governance: emerging practices and the incomplete legal framework for citizen and stakeholder voice. Missouri Journal of Dispute Resolution 2009(2):269-326.

Bodansky, D. 1999. The legitimacy of international governance: a coming challenge for international environmental law? American Journal of International Law 93:596-624. http://dx.doi.org/10.2307/2555262

Bodin, O., and B. I. Crona. 2009. The role of social networks in natural resource governance: what relational patterns make a difference? Global Environmental Change 19:366-374. http://dx.doi.org/10.1016/j.gloenvcha.2009.05.002

Boyle, M., J. Kay, and B. Pond. 2001. Monitoring in support of policy: an adaptive ecosystem approach. Pages 116-137 in T. Munn, editor. Encyclopedia of Global Environmental Change. Volume 4. Wiley, New York, New York, USA.

Camacho, A. E. 2009. Adapting governance to climate change: managing uncertainty through a learning infrastructure. Emory Law Journal 59(1):1-77.

Cosens, B. 1998. The 1997 water rights settlement between the state of Montana and the Chippewa Cree Tribe of the Rocky Boy's Reservation - the role of community and of the trustee. UCLA Journal of Environmental Law and Policy 16:255-295.

Cosens, B. 2008. Resolving conflict in non-ideal, complex systems: solutions for the law-science breakdown in environmental and natural resource law. Natural Resources Journal 48:257-301.

Cosens, B. 2010. Transboundary river governance in the face of uncertainty: resilience theory and the Columbia River Treaty. University of Utah Journal of Land Resources, and Environmental Law 30:229-265.

Cosens, B., and M. K. Williams. 2012. Resilience and water governance: adaptive governance in the Columbia River basin. Ecology and Society 17(4): 3. http://dx.doi.org/10.5751/ ES-04986-170403

Doremus, H. 2005. Science plays defense: natural resource management in the Bush Administration. Ecology Law Quarterly 32:249-305.
Esty, D. C. 2006. Good governance at the supranational scale: globalizing administrative law. Yale Law Journal 115:1490-1562. http://dx.doi.org/10.2307/20455663

European Union. 2000. The EU Water Framework Directive - integrated river basin management for Europe. Council Directive 2000/60/EC, Official Journal (OJ L 327) 1-73 (EC). [online] URL: http://ec.europa.eu/environment/water/waterframework/index en.html

Folke, C., T. Hahn, P. Olsson, and J. Norberg. 2005. Adaptive governance of social-ecological systems. Annual Review of Environmental Resources 30:441-473. http://dx.doi.org/10.1146/ annurev.energy.30.050504.144511

Gladwell, M. 2000. The tipping point: how little things can make a big difference. Little Brown, New York, New York, USA.

Global Water Partnership. 2000. Integrated water resources management. TAC Background Papers No. 4. Global Water Partnership, Stockholm, Sweden. [online] URL: http://www. gwptoolbox.org/images/stories/gwplibrary/background/tac 4 english. pdf

Global Water Partnership. 2002. IWRM ToolBox. Version 2. Global Water Partnership, Stockholm, Sweden. [online] URL: http://www.gwptoolbox.org/images/stories/Docs/toolboxeng. pdf

Hirt, P. W., and A. M. Sowards. 2012. The past and future of the Columbia River. Pages 115-136 in B. Cosens, editor. The Columbia River Treaty revisited: transboundary river governance in the face of uncertainty. Oregon State University Press, Corvallis, Oregon, USA.

Holling, C. S. 1973. Resilience and stability of ecological systems. Annual Review of Ecology and Systematics 4:1-24. http://dx.doi.org/10.1146/annurev.es.04.110173.000245

Holling, C. S., editor. 1978. Adaptive environmental assessment and management. Wiley and Sons, London, UK.

Holling, C. S. 2001. Understanding the complexity of economic, ecological and social systems. Ecosystems 4:390-405. http://dx.doi.org/10.1007/s10021-001-0101-5

Holling, C. S., and L. H. Gunderson. 2002. Resilience and adaptive cycles. Pages 25-62 in L. H. Gunderson and C. S. Holling editors. Panarchy: understanding transformations in human and natural systems. Island Press, Washington, D.C., USA.

Huitema, D., E. Mostert, W. Egas, S. Moellenkamp, C. PahlWostl, and R. Yalcin, 2009. Adaptive water governance: assessing the institutional prescriptions of adaptive (co) management from a governance perspective and defining a research agenda. Ecology and Society 14(1): 26. URL: http:// www.ecologyandsociety.org/vol14/iss1/art26/ 
Kosso, P. 2007. Scientific understanding. Foundations of Science 12(2):173-188. http://dx.doi.org/10.1007/s10699-006-0002-3

Lee, K. N. 1993. Compass and gyroscope: integrating science and politics for the environment. Island Press, Washington, D. C., USA.

Lee, K. N. 1999. Appraising adaptive management. Conservation Ecology 3(2): 3. URL: http://www.consecol. org/vol3/iss2/art3/

Long, J. 2009. From warranted to valuable belief: local government, climate change, and giving up the pickup to save Bangladesh. Natural Resources Journal 49(3/4):743-800.

Nez Perce Tribe, State of Idaho, and United States Federal Government. 2004. Mediator's Term Sheet of April 20, 2004. Snake River Water Rights Settlement. [online] URL: http:// www.srba.state.id.us/FORMS/Mediator\%20term\%20sheet.pdf

O'Reilly, K. 2007. Science, policy, and politics: the impact of the Information Quality Act on risk-based regulatory activity at the EPA. Buffalo Environmental Law Journal 14:249-287.

Roth, D., R. Boelens, and M. Zwarteveen, editors. 2005. Liquid relations: contested water rights and legal complexity. Rutgers University Press, New Brunswick, New Jersey, USA.

Ruhl, J. B. 2011. General design principles for resilience and adaptive capacity in legal systems. North Carolina Law Review 89:1373-1403.

Ruhl, J. B., and J. Salzman, 2006. In defense of regulatory peer review. Washington University Law Review 84:1-61.

Ruhl, J. B., and J. Salzman. 2010. Climate change, dead zones, and massive problems in the administrative state: guidelines for whittling away. California Law Review 98:59-120.

Stewart, R. 2003. Administrative law in the Twenty-First Century. Essay. New York University Law Review 78:437-460.

Stys, J. J. 2011. Non-profit involvement in disaster response and recovery. Prepared for the Center for Law, Environment, Adaptation and Resources (CLEAR) at the University of North Carolina School of Law, Chapel Hill, North Carolina, USA. [online] URL: http://www.law.unc.edu/documents/clear/ nonprofit.pdf

U.S. Department of Homeland Security. National Incident Management System (NIMS) frequently asked questions. Federal Emergency Management Agency, U.S. Department of Homeland Security, Washington, D.C., USA. [online] URL: http://www.fema.gov/frequently-asked-questions-2

U.S. Forest Service. 2000. International programs: disaster mitigation program. U.S. Forest Service, Washington, D.C.,
USA. [online] URL: http://www.fs.fed.us/global/aboutus/ dmp/welcome.htm

U.S. Geological Survey (USGS) Patuxent Wildlife Research Center. Manager's monitoring manual. USGS, Reston, Virginia, USA. [online] URL: http://www.pwrc.usgs.gov/ monmanual/

Wagner, W. E. 1995. The science charade in toxic risk regulation. Columbia Law Review 95:1613-1723. http://dx. doi.org/10.2307/1123193

Walker, B., C. S. Holling, S. R. Carpenter, and A. Kinzig. 2004. Resilience, adaptability and transformability in socialecological systems. Ecology and Society 9(2): 5. [online] URL: http://www.ecologyandsociety.org/vol9/iss2/art5

Walker, B., and D. Salt. 2006. Resilience thinking: sustaining ecosystems and people in a changing world. Island Press, Washington, D.C., USA.

Zaring, D. 2009. Three challenges for regulatory networks. International Lawyer 43:211-217.

Zellmer, S., and L. H. Gunderson. 2009. Why resilience may not always be a good thing: lessons in ecosystem restoration from Glen Canyon and the Everglades. Nebraska Law Review 87:893-949. 